Marko Valčić, Ph.D.

E-mail: mvalcic@pfri.hr

University of Rijeka, Faculty of Maritime Studies, Studentska 2, 51000 Rijeka, Croatia

Roko Dejhalla, D.Sc.

E-mail: roko@riteh.hr

University of Rijeka, Faculty of Engineering, Vukovarska 58, 51000 Rijeka, Croatia

\title{
Neural Network Prediction of Open Water Characteristics of Ducted Propeller
}

\begin{abstract}
Dynamic positioning system is a computer-controlled system which enables maintaining the marine vessel's position and heading by means of propellers and active thrusters. In order to improve the efficiency of the heavily loaded propeller at low advance velocity, the azimuth thrusters with a nozzle around the propeller are mostly used. The paper deals with the development of the neural network prediction model for the Wageningen ducted propeller series. The aim is to create a prediction tool that provides the estimation of the open water characteristics of the four blade Ka series in combination with the 19A accelerating nozzle. For this purpose, two layered feedforward neural network is used. The proposed neural network model provides the possibility for a more general modelling of azimuth thruster in usually very complex hydrodynamic propulsion model of the dynamically positioned marine vessel.
\end{abstract}

Key words: dynamic positioning, azimuth thruster, ducted propeller, open water characteristics, feedforward neural network

\section{Introduction}

Knowing all the significant characteristics of the ducted propeller is crucial in modelling propulsion systems for dynamically positioned vessels. Although some other types of thrusters are used for the propulsion of these vessels, such as azipods, tunnel thrusters, waterjets, classic screws with a rudder, etc., the fact remains that the azimuth ducted propeller is the one most commonly used in these vessels. The reason lies primarily in the possibility of generating thrust in all directions, but also in very favourable hydrodynamic properties typical for exploitation conditions of dynamically positioned vessels which are very close to the bollard pull test, i.e. when the advance velocity is either relatively low or almost equal to zero. 
In this paper, due to the afore mentioned reasons, the emphasis is placed on the analysis and modelling of the typical, and very often used in research works, Wageningen $K_{a}$ series of ducted propellers, i.e. propellers $K_{a} 3-65, K_{a} 4-55, K_{a} 4-70$ and $K_{a} 5-75$ in nozzles No. 19A and No. 37. Without any publicly released test results for different types of propellers without (B series) and with the nozzle ( $\mathrm{K}_{\mathrm{a}}$ series), which have been repeatedly reported by scientists and researchers from the Dutch Institute MARIN of Wageningen, any further research in this area would be considerably difficult, probably impossible. For the purpose of this paper, the results published by M.W.C. Oosterveld in [1] are mainly used.

The application of artificial neural networks in the modelling of hydrodynamic characteristics of marine propellers is certainly not an entirely new concept, but regardless of the several existing papers [2] [3] [4], this area is surely not sufficiently explored. This especially refers to the azimuth thrusters (ducted propellers) which in turn are of particular importance to vessels with dynamic positioning, regardless of whether the propellers are with fixed or controllable pitch.

The artificial neural network has been applied to the ducted propellers $K_{a}$ 4-55 and $K_{a} 4-70$, both in the nozzle 19A, in order to create such a network which would enable hydrodynamic characteristics of the propeller from $\mathrm{K}_{\mathrm{a}}$ series with four blades and expanded area ratio from the interval $[0.55,0.70]$ to be determined.

\section{Wageningen $K_{a}$ screw series in accelerating nozzle}

The combination of the propeller and the nozzle represents one of the most common propulsion units on vessels with dynamic positioning systems. If such a propulsion unit can be freely rotated $360^{\circ}$ around its vertical axis (Fig. 1), then it comes to the so-called azimuth ducted propeller. Among other propulsion units, tunnel thrusters could also be used, as well as conventional propellers with rudder, waterjets, etc., but they are not the subject of this paper.

The nozzle can be accelerating or decelerating, depending on its geometric characteristics. Marine propellers in accelerating nozzle are mainly used when the propeller is extremely loaded or when the restrictions with respect to the allowed diameter of the propeller are necessary. Given that this nozzle creates a positive thrust, it also increases the efficiency of the extremely loaded propellers.

In the last 50 years there were numerous studies and researches related to marine propellers with and without nozzle. Perhaps the best known ones are those derived from Wageningen Institute MARIN (Wageningen, The Netherlands) by Oosterveld [1] and Kuiper [5]. In their papers/reports, the details of these studies can be found. Anyhow, it should be noted that without their publicly released results it would have been almost impossible for numerous studies about propulsion units and systems to be conducted.

Even the theoretical calculations clearly indicate that the application of accelerating nozzle increases the efficiency of loaded propellers [1]. If the load of the propeller 
increases, then the nozzle length $L$ should be longer, while at lesser loads a shorter nozzle is recommended. However, even with extreme loads, the nozzle $L / D$ ratio should not be greater than 1.0 (Fig. 2).

The initial tests with different accelerating nozzles were conducted with the Wageningen $B$-screw series, whereof more information can be found in [1] and [5]. Due to certain deficiencies of $B$-series ducted propellers (cavitation), the specific $\mathrm{K}_{\mathrm{a}}$ series of propellers was developed in the former Netherlands Ship Model Basin (NSMB) and today's Maritime Research Institute Netherlands (MARIN). The examined propellers of particular importance are $\mathrm{K}_{\mathrm{a}} 3-65, \mathrm{~K}_{\mathrm{a}} 4-55, \mathrm{~K}_{\mathrm{a}} 4-70$ and $\mathrm{K}_{\mathrm{a}}$ 5-75 with the diameter of $D=2400 \mathrm{~mm}$ and clearance of $1 \mathrm{~mm}$ in the combination with nozzle No. 19A $(L / D=0.5)$, and the combination of propeller $\mathrm{K}_{\mathrm{a}} 4-70$ in nozzle No. $37(L / D=0.5)$. The details about this series can also be found in [1] and [5]. The aforementioned nozzles No. 19A and No. 37 are also often used in practice because of their production simplicity and possession of many desirable hydrodynamic characteristics. In this paper, they are used because of the numerous data available which are required for the propulsion modelling of dynamically positioned vessels for the combination with the propeller $\mathrm{K}_{\mathrm{a}} 4-70$.

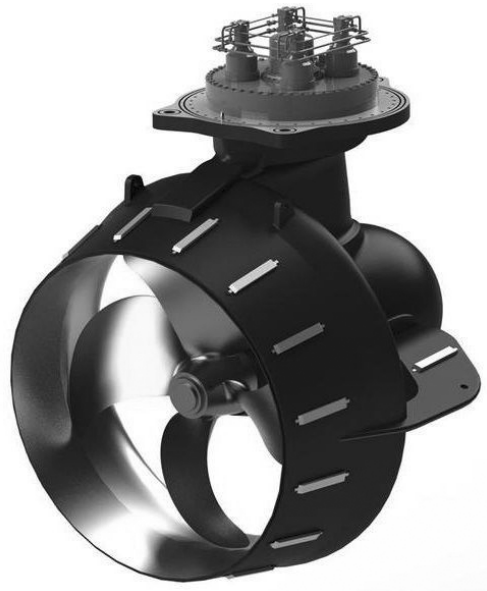

Figure 1. Azimuth thruster Source: [6]

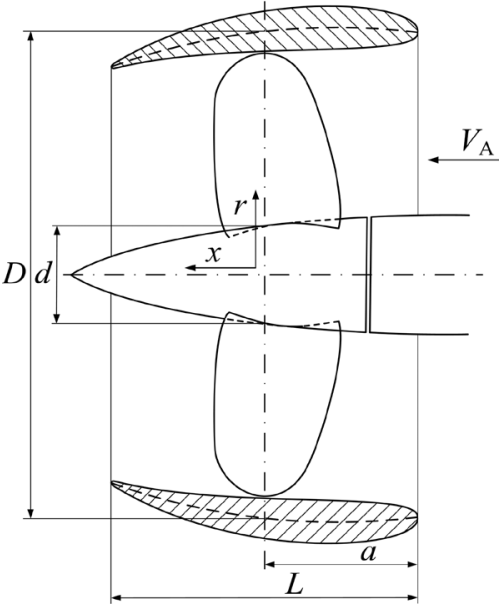

Figure 2. Ducted propeller basic dimensions Source: [1]

The forces and the torques generated by the ducted propeller are usually expressed by the so-called non-dimensional open water characteristics which are of completely general nature with regard to specific geometric configurations of the propeller and the nozzle. These characteristics are: 
(i) Thrust coefficient $K_{T}$

$$
K_{T}=\frac{T}{\rho n^{2} D^{4}},
$$

(ii) Torque coefficient $K_{Q}$

$$
K_{Q}=\frac{Q}{\rho n^{2} D^{5}},
$$

(iii) Nozzle thrust coefficient $K_{T N}$

$$
K_{T N}=\frac{T_{N}}{\rho n^{2} D^{4}},
$$

(iv) Advance coefficient $J$

$$
J=\frac{V_{\mathrm{A}}}{n D},
$$

(v) Open water efficiency of a propeller $\eta_{0}$

$$
\eta_{0}=\frac{J}{2 \pi} \frac{K_{T}}{K_{Q}},
$$

where $T$ is the thrust, $\mathrm{kN} ; Q$ is the torque, $\mathrm{kNm} ; T_{N}$ is the nozzle thrust, $\mathrm{kN} ; V_{A}$ is the speed of advance, $\mathrm{m} / \mathrm{s} ; n$ is the propeller revolution, $\mathrm{s}^{-1} ; D$ is the propeller diameter, $\mathrm{m} ; \rho$ is the sea water density, $\mathrm{t} / \mathrm{m}^{3}$.

The test results of the propellers $K_{a} 3-65, K_{a} 4-55, K_{a} 4-70$ and $K_{a} 5-75$ in the combination with the nozzle no. 19A can be aggregated using multidimensional nonlinear polynomial regression and so the coefficients of thrust $\left(K_{T}, K_{T N}\right)$ and torque $\left(K_{Q}\right)$ are expressed as polynomials in the function of the advance coefficient $J$ and the pitch ratio $P / D$, where $P$ represents the propeller pitch which is defined as the axial shift of a point on the propeller during one complete revolution of $D \pi$.

Oosterveld shows in [1] that it is sufficient to choose the multivariable sixth- or at the most seventh-order polynomials, so for $K_{T}, K_{T N}$ and $K_{Q}$ they can be written as the regression polynomials of two variables in the following form:

$$
\begin{aligned}
& K_{T}=\sum_{x=0}^{n} \sum_{y=0}^{n} A_{x, y}(P / D)^{x} J^{y}, \\
& K_{T N}=\sum_{x=0}^{n} \sum_{y=0}^{n} B_{x, y}(P / D)^{x} J^{y}, \\
& K_{Q}=\sum_{x=0}^{n} \sum_{y=0}^{n} C_{x, y}(P / D)^{x} J^{y},
\end{aligned}
$$


where the coefficient values $A_{x, y}, B_{x, y}$ and $C_{x, y}(x=0,1, \ldots, 6$ and $y=0,1, \ldots, 6)$ can be found in [1] and [7], wherein $n=6$ for combinations $\left\{\mathrm{K}_{\mathrm{a}} 3-65\right.$ and No. 19A $\},\left\{\mathrm{K}_{\mathrm{a}}\right.$ 4-70 and No. 19A $\}$ and $\left\{\mathrm{K}_{\mathrm{a}}\right.$ 5-75 and No. $\left.19 \mathrm{~A}\right\}$, and $n=7$ for combinations $\left\{\mathrm{K}_{\mathrm{a}} 4-55\right.$ and No. 19A $\}$ and $\left\{K_{a} 4-70\right.$ and No. 37$\}$.

In order to avoid double-sum calculations using nested loops, and to significantly increase the calculation speed, relations (6), (7) and (8) are further vectorized. For this purpose, the following matrices and vectors are defined:

(i) Matrix of coefficients $A_{x, y}$

$$
\mathbf{A}=\left[\begin{array}{cccc}
A_{0,0} & A_{0,1} & \cdots & A_{0, n} \\
A_{1,0} & A_{1,1} & \cdots & A_{1, n} \\
\vdots & \vdots & \ddots & \vdots \\
A_{n, 0} & A_{n, 1} & \cdots & A_{n, n}
\end{array}\right]
$$

(ii) Matrix of coefficients $B_{x, y}$

$$
\mathbf{B}=\left[\begin{array}{cccc}
B_{0,0} & B_{0,1} & \cdots & B_{0, n} \\
B_{1,0} & B_{1,1} & \cdots & B_{1, n} \\
\vdots & \vdots & \ddots & \vdots \\
B_{n, 0} & B_{n, 1} & \cdots & B_{n, n}
\end{array}\right]
$$

(iii) Matrix of coefficients $C_{x, y}$

$$
\mathbf{C}=\left[\begin{array}{cccc}
C_{0,0} & C_{0,1} & \cdots & C_{0, n} \\
C_{1,0} & C_{1,1} & \cdots & C_{1, n} \\
\vdots & \vdots & \ddots & \vdots \\
C_{n, 0} & C_{n, 1} & \cdots & C_{n, n}
\end{array}\right]
$$

(iv) Vector of pitch ratio $P / D$

$$
\mathbf{R}=\left[\begin{array}{llll}
(P / D)^{0} & (P / D)^{1} & \cdots & (P / D)^{n}
\end{array}\right]^{\mathrm{T}}
$$

(v) Vector of advance coefficient $J$

$$
\mathbf{J}=\left[\begin{array}{llll}
J^{0} & J^{1} & \cdots & J^{n}
\end{array}\right]^{\mathrm{T}} .
$$

Using matrices $\mathbf{A}, \mathbf{B}, \mathbf{C}, \mathbf{R}$ and $\mathbf{J}$, relations (6), (7) and (8), i.e. double sums therein, can be expressed by means of vectorization in the following matrix form: 


$$
\begin{aligned}
& K_{T}=\mathbf{J}^{\mathrm{T}} \mathbf{A}^{\mathrm{T}} \mathbf{R}, \\
& K_{T N}=\mathbf{J}^{\mathrm{T}} \mathbf{B}^{\mathrm{T}} \mathbf{R}, \\
& K_{Q}=\mathbf{J}^{\mathrm{T}} \mathbf{C}^{\mathrm{T}} \mathbf{R} .
\end{aligned}
$$

Taking into account the well-known property of multiplied transposed matrices

$$
\mathbf{X}^{\mathrm{T}} \mathbf{Y}^{\mathrm{T}}=(\mathbf{Y X})^{\mathrm{T}},
$$

relations for $K_{T}, K_{T N}$ and $K_{Q}$ can be written as:

$$
\begin{aligned}
& K_{T}=(\mathbf{A J J})^{\mathrm{T}} \mathbf{R}, \\
& K_{T N}=(\mathbf{B J})^{\mathrm{T}} \mathbf{R}, \\
& K_{Q}=(\mathbf{C J})^{\mathrm{T}} \mathbf{R} .
\end{aligned}
$$

Expressions (15), (16) and (17) are very suitable for programming in MATLAB. For this purpose, the $\mathrm{m}$-function polregmodel. $m$ was created, having matrices $\mathbf{A}, \mathbf{B}$ and $\mathbf{C}$ as well as the values of $J$ and $P / D$ as the function inputs where the values of $K_{T}, K_{T N}$ and $K_{Q}$ are the function outputs.

Although $K_{T}, K_{T N}, K_{Q}$ and $\eta_{0}$ are functions of two variables $J$ and $P / D$, their visualization is usually planar, which means they are shown as curves, i.e. functions of one variable $J$, for the selected (constant) values of the pitch ratio $P / D$. The usual interval for $J$ is $\left[0, J\left(\eta_{0}=0\right)\right]$, and the values for $P / D$ are of the set $\{0.6,0.8,1.0$, $1.2,1.4\}$. For the selected pitch ratio $P / D$, the value $J\left(\eta_{0}=0\right)$ corresponds to that value of the advance coefficient $J$ for which $\left(\eta_{0}=0\right)$ applies. An example of such a visualization of hydrodynamic characteristics $K_{T}, K_{T N}, K_{Q}$ and $\eta_{0}$ for the propeller $\mathrm{K}_{\mathrm{a}}$ 4-70 in the nozzle No. 19A is shown in Figure 3.

The total thrust produced by the ducted propeller can be divided into two components:

- the algebraic sum of the propeller thrust and the nozzle thrust,

- the second-order effects caused by the mutual influence of the propeller and the nozzle.

Assuming the first approximation, the total thrust $T$ from (1) can be written as

$$
T=T_{P}+T_{N},
$$

where $T_{P}$ is the propeller thrust, and $T_{N}$ is the nozzle thrust. In non-dimensional form, the same can be written as

$$
K_{T}=K_{T P}+K_{T N},
$$

where the non-dimensional factor $\rho n^{2} D^{4}$ is the same as in (1). 


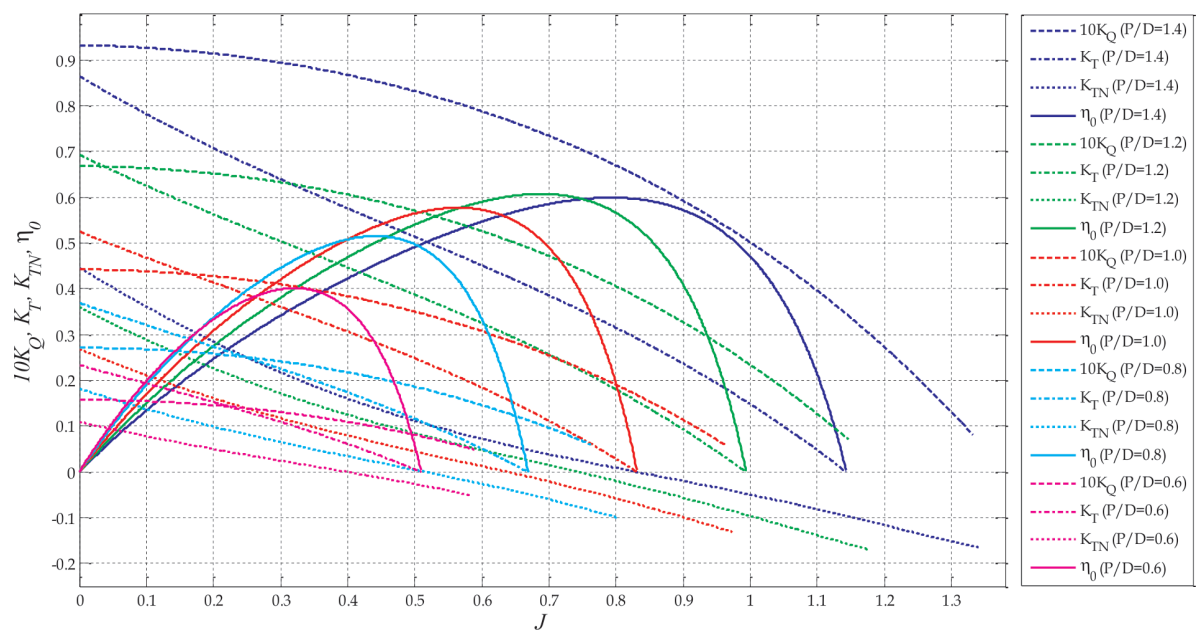

Figure 3. Visualization of the open water test results for the propeller $K_{a} 4-70$ in the nozzle $19 \mathrm{~A}$

On the other hand, the torque characteristics cannot be decomposed into two components, because the propeller fully absorbs the torque of the engine, i.e. of the prime mover (diesel engine, electromotor, etc.). Generally, the part of the thrust generated by the nozzle considering the overall thrust $T$ is also a variable which changes in dependence on the advance coefficient $J$. In applications of azimuth thrusters in the merchant navy and offshore industry, the absolute majority of them are made with accelerating nozzles. In such thrusters the ratio $K_{T N} / K_{T}$ takes the value of 0.5 in the bollard pull conditions or generally in the conditions where $V_{A} \approx 0$, which is a common operation mode of dynamic positioning. In conditions of free sailing, the value of $K_{T N} / K_{T}$ drops to values of 0.05 to 0.10 . If the advance coefficient increases to some highly critical value, the nozzle thrust will change direction (Fig. 3), and it will begin to act as a drag. However, it should be emphasized that such a situation is almost impossible in practice.

\section{Feedforward neural network}

On the basis of the known matrices (9) and (11), it is easy to determine the thrust and torque coefficients from the expressions (15) and (17) for some of the examined propellers of the $\mathrm{K}_{\mathrm{a}}$ series. Unfortunately, the available polynomials are only applicable to certain propellers with the pitch ratio values $P / D=\{0.6,0.8,1.0,1.2,1.4\}$. For other values, where $P / D \in\langle 0.6,1.4\rangle \backslash\{0.8,1.0,1.2\}$, generally the interpolation by $P / D$ needs to be used. Considering that the regression polynomials are only known for $P / D=\{0.6,0.8,1.0,1.2,1.4\}$, in this case the thrust and torque coefficients can be considered as functions of one variable and such are typically plotted on $K_{T}-J$, i.e. $K_{Q}-J$ diagrams (Fig. 3). 
One of the two main goals of this paper is to create a neural network which will expand the set of values $P / D=\{0.6,0.8,1.0,1.2,1.4\}$ on the interval $[0.6,1.4]$. The other goal is to further extend the possibilities of such a network, in a way to allow the determination of hydrodynamic characteristics of the propellers with different expanded area ratios $A_{\mathrm{E}} / A_{\mathrm{O}}$. Since a relatively small sample of the disposable measurements is available, the additional data are provided by the vertical interpolation. In fact, the determination of the thrust and torque coefficients for an intermediate value of $P / D$ ratio, can be easily determined on the basis of the length ratio (Fig. 4).
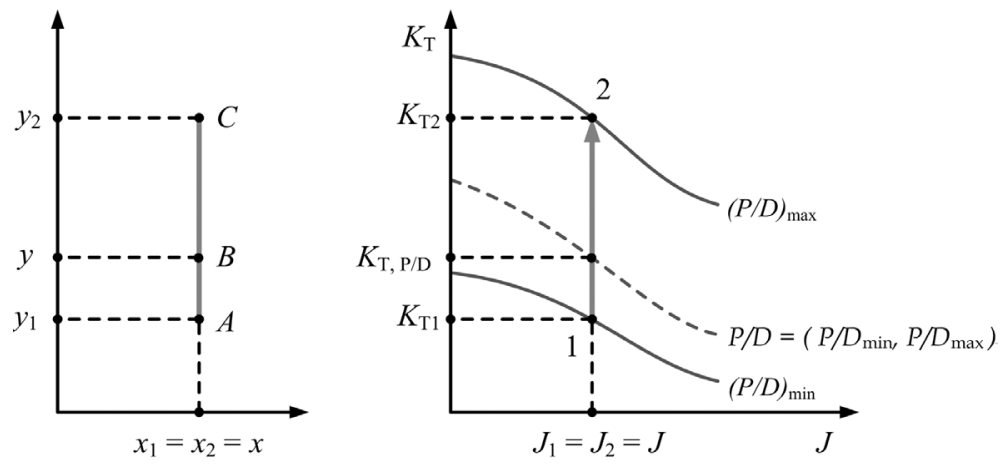

Figure 4. Length ratio and vertical interpolation for thrust coefficient

According to Fig. 4, the length ratio can be defined as

$$
\lambda=\frac{\mathrm{d}(\mathrm{A}, \mathrm{B})}{\mathrm{d}(\mathrm{B}, \mathrm{C})} \in\langle 0, c\rangle, c \rightarrow+\infty \Rightarrow y=\frac{y_{1}+\lambda y_{2}}{1+\lambda},
$$

which can be applied to the thrust coefficient $K_{T}$ (Fig. 4) as following:

$$
\lambda_{P / D}=\frac{P / D-(P / D)_{\min }}{(P / D)_{\max }-P / D} \Rightarrow K_{T, P / D}=\frac{K_{T 1}+\lambda_{P / D} K_{T 2}}{1+\lambda_{P / D}} \quad \text { (for } J=\text { const.). }
$$

The same is for the torque coefficient. During the data preparation for the neural network, the interpolation was applied by segments, i.e. for

$$
\left\langle(P / D)_{\min },(P / D)_{\max }\right\rangle=\{\langle 0.6,0.8\rangle,\langle 0.8,1.0\rangle,\langle 1.0,1.2\rangle,\langle 1.2,1.4\rangle\}
$$

with the step of 0.025 .

The available data, i.e. the ones released by the MARIN Institute include the following combinations of propellers and the corresponding nozzles: $\left\{\mathrm{K}_{\mathrm{a}} 3-65\right.$ and No. 19A $\},\left\{K_{a} 4-55\right.$ and No. 19A $\},\left\{K_{a} 4-70\right.$ and No. 19A $\},\left\{K_{a}\right.$ 5-75 and No. 19A $\}$, and $\left\{\mathrm{K}_{\mathrm{a}}\right.$ 4-70 and No. 37\}. Considering the expanded area ratios, it is clear that the extending of the neural network possibilities can only be executed with combinations $\left\{K_{a} 4-55\right.$ and No. 19A $\}$ and $\left\{K_{a} 4-70\right.$ and No. 19A $\}$ since these are the only two ava- 
ilable propellers with the same number of blades $(Z=4)$. For this reason, the neural network was used to analyse the changes in the expanded area ratio on the interval $A_{\mathrm{E}} / A_{\mathrm{O}} \in[0.55,0.70]$ of the propellers from $\mathrm{K}_{\mathrm{a}}$ series in the nozzle $19 \mathrm{~A}$ with four blades. The thrust and torque coefficients for the intermediate values of the expanded area ratios on the interval $[0.55,0.70]$ were also obtained by the vertical interpolation (21) for the requirement of the neural network.

The MATLAB software [8] was used for training, validation and testing of the neural network. For this purpose, the $3 \mathrm{D}$ input matrix $\left[J, P / D, A_{E} / A_{O}\right]$ was generated, which the neural network maps to the matrix $\left[K_{T}, K_{Q}\right]$. In other words, the neural network in this case presents a mapping of the following form

$$
\left[J, P / D, A_{\mathrm{E}} / A_{\mathrm{O}}\right] \stackrel{N N}{\longrightarrow}\left[K_{T}, K_{O}\right] .
$$

Considering the data preparation according to the MATLAB notation, the values of the input parameters were selected as $J=0: 0.01: 1.34, P / D=0.6: 0.025: 1.4$ and $A_{E} / A_{O}=0.55: 0.01: 0.07$. It is clear that $\operatorname{dim}(J)=135, \operatorname{dim}(P / D)=33$ and $\operatorname{dim}\left(A_{E} / A_{O}\right)$ $=16$, which yields $\operatorname{dim}\left(\left[J, P / D, A_{E} / A_{O}\right]\right)=3 \times 71280$ for the input matrix.

For the neural network, the two-layered feedforward network with the error backpropagation was selected, as one of the most applicable in the approximation problems [9]. The structure of the feedforward neural network for the approximation of multivariable function

$$
y=f\left(x_{1}, x_{2}, \ldots, x_{n}\right)
$$

presupposes $n$ neurons in the input layer and one neuron in the output layer. The number of neurons $m$ in the hidden layer can vary from case to case. A schematic structure representation of such a network is shown in Fig. 5.

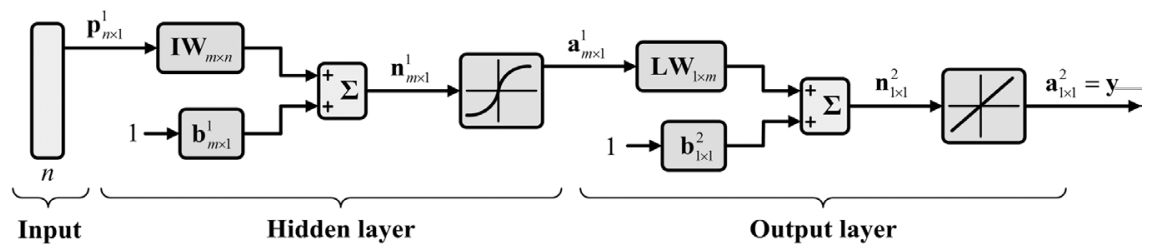

Figure 5. Layer diagram of the two-layered feedforward neural network

If the input vector $\mathbf{p}_{n \times 1}^{1}$ is presented as the input to the feedforward neural network, then the output $\mathbf{a}_{m \times 1}^{1}$ from the hidden layer is determined by the expression

$$
\mathbf{a}_{m \times 1}^{1}=\operatorname{tansig}\left(\mathbf{I} \mathbf{W}_{m \times n} \cdot \mathbf{p}_{n \times 1}^{1}+\mathbf{b}_{m \times 1}^{1}\right),
$$

where $\mathbf{I W}_{m \times n}$ is the weight coefficients matrix of the hidden layer, and $\mathbf{b}_{n \times 1}^{1}$ is the bias vector for each hidden neuron in the hidden layer.

When the output from the hidden layer $\mathbf{a}_{m \times 1}^{1}$ is presented as the input of the output layer, then the final output $\mathbf{a}_{1 \times 1}^{2}=\mathbf{y}$ from the neural network is calculated by the expression 


$$
\mathbf{y}=\mathbf{a}_{1 \times 1}^{2}=\operatorname{purelin}\left(\mathbf{L W}_{1 \times m} \cdot \mathbf{a}_{m \times 1}^{1}+\mathbf{b}_{1 \times 1}^{1}\right),
$$

where $\mathbf{L} \mathbf{W}_{1 \times m}$ is the weight coefficients matrix of the output layer, and $\mathbf{b}_{1 \times 1}^{1}$ is the bias vector of the output neuron.

In the feedforward learning phase the values of the input vector are taken from the learning set and they are used to calculate the components of the output vector. For this calculation it is necessary for the initial values of weight coefficients to be set in matrices IW and $\mathbf{L W}$. These values are determined by the random number generator for the hidden layer. The weights of the output layer can also be determined in this manner, although this does not ensure a quick learning start of the neural network.

In the feedback learning phase, training errors are calculated based on the network responses, i.e. network outputs, and on the desired, i.e. target, outputs. On the basis of these errors, the values of weight coefficients between individual layers are updated. The entire process is repeated iteratively for each $(n+1)$ - tuple of the total $N$ inputoutput data from the learning set, until the error lesser than or equal to some acceptable value is achieved. In this context, the acceptable error represents the allowed deviation between the response of the neural network and the desired (target) output. In other words, based on the selected cost function, the values of weight coefficients are changed, i.e. adapted by means of some appropriate non-linear programming algorithm.

According to (22), the selected network has three neurons in the input layer, and two in the output layer. The number of neurons in the hidden layer has been varied, but 20 neurons were adopted in the end. Schematic representation of the architecture of the created network is shown in Fig. 6.

Hidden layer

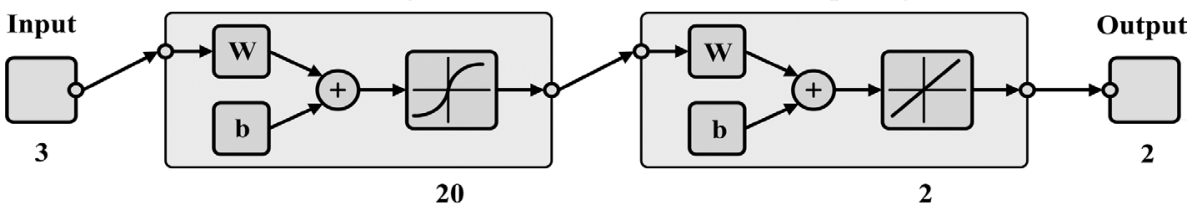

Figure 6. Neural network architecture for determination of hydrodynamic characteristics of ducted propeller

The network was trained using the Levenberg-Marquardt learning algorithm which is one of the most appropriate and commonly used for training error backpropagation neural networks. More details about this algorithm can be found in [10].

The samples of the input matrix were randomly divided into three groups: samples for training $(70 \%)$, samples for validation (15\%) and samples for testing $(15 \%)$. The generalization possibilities of the network were examined by the validation process while the independent verification of the network performance was made by testing the data set previously excluded from the network during the training and validation phases. 
The performance of the created network was evaluated by the mean square error (MSE) and by the correlation coefficient $(R)$ between the 'real' thrust and torque coefficients and those obtained as the network outputs, i.e. network responses. The performance indexes were calculated for each of the three phases particularly, with respect to the thrust and torque coefficients. The training was conducted in 40 iterations. The performance indexes are presented in Table 1 and the obtained results show excellent approximation capabilities of the neural network.

Table 1. Evaluation performance of neural network during training, validation and testing

\begin{tabular}{|l|c|c|c|c|c|}
\hline \multirow{2}{*}{ Phase } & \multirow{2}{*}{$\begin{array}{c}\text { No. of } \\
\text { samples }\end{array}$} & \multicolumn{2}{c|}{ Thrust coefficient $K_{T}$} & \multicolumn{2}{c|}{ Torque coefficient $K_{Q}$} \\
\cline { 3 - 6 } & & $M S E$ & $R$ & $M S E$ & $R$ \\
\hline Training & 49896 & $1.02544 \cdot 10^{-5}$ & 0.999968 & $8.37001 \cdot 10^{-6}$ & 0.999944 \\
\hline Validation & 10692 & $1.02196 \cdot 10^{-5}$ & 0.999968 & $8.43980 \cdot 10^{-6}$ & 0.999944 \\
\hline Testing & 10692 & $1.04394 \cdot 10^{-5}$ & 0.999967 & $8.59005 \cdot 10^{-6}$ & 0.999942 \\
\hline
\end{tabular}

\section{Results}

The obtained mapping $\left[K_{T}, K_{O}\right]=f_{N N}\left(\left[J, P / D, A_{\mathrm{E}} / A_{\mathrm{O}}\right]\right)$ represents a 5-D object in a MATLAB which for any value of $J \in[0,1.34], P / D \in[0.6,1.4]$ and $A_{\mathrm{E}} / A_{\mathrm{O}} \in[0.55,0.70]$ gives the ordered pair of the thrust and torque coefficients at the output, i.e. $\left(K_{T}, K_{Q}\right)$. The visualization of the 5-D object can be decomposed into two 4-D objects, particularly for $K_{T}$ and $K_{Q}$, but even then it is relatively complicated. It is recommended to set the $K_{T}$ and $K_{Q}$ on the ordinate ( $z$ axis) of a 3-D coordinate system, $J$ and $P / D$ on the $x$ and $y$ axes, and to decompose $A_{E} / A_{O}$ on the surfaces.

For simplicity reasons, the following shows several specific cases in 2-D, i.e. the usual $K_{T}-J$ and $K_{Q}-J$ diagrams, in order to visually evaluate the approximation possibilities of the created neural network. Usually, the diagrams show the curves for different pitch ratios $P / D$ and constant expanded area ratio $A_{E} / A_{O}$. The figures below show quite the opposite situation, i.e. the curves with different $A_{E} / A_{O}$ and constant $P / D$ are displayed. Thus, Fig. 7 shows the case for $P / D=1.2$ and $A_{E} / A_{O}=\{0.55$, $0.58,0.61,0.68,0.70\}$ and Fig. 8 presents the case for $P / D=0.8$ and $A_{E} / A_{O}=\{0.55$, $0.58,0.61,0.68,0.70\}$. 


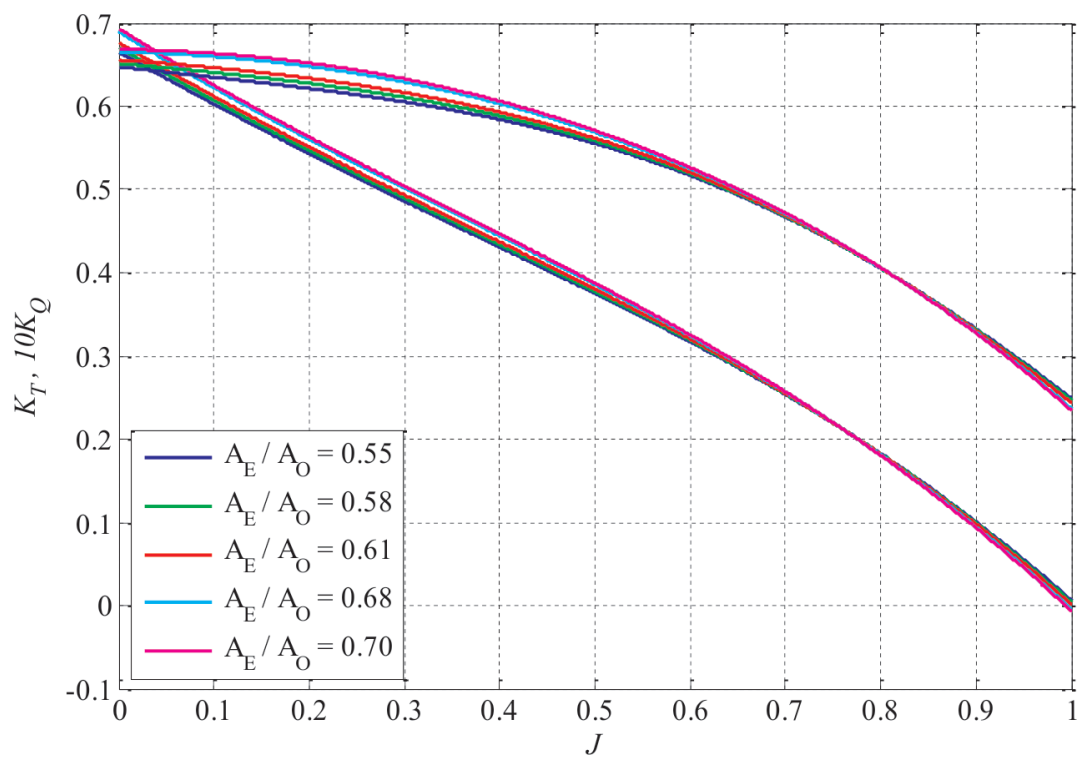

Figure 7. Neural network response for $P / D=1.2$ and $A_{E} / A_{O}=\{0.55,0.58,0.61,0.68,0.70\}$

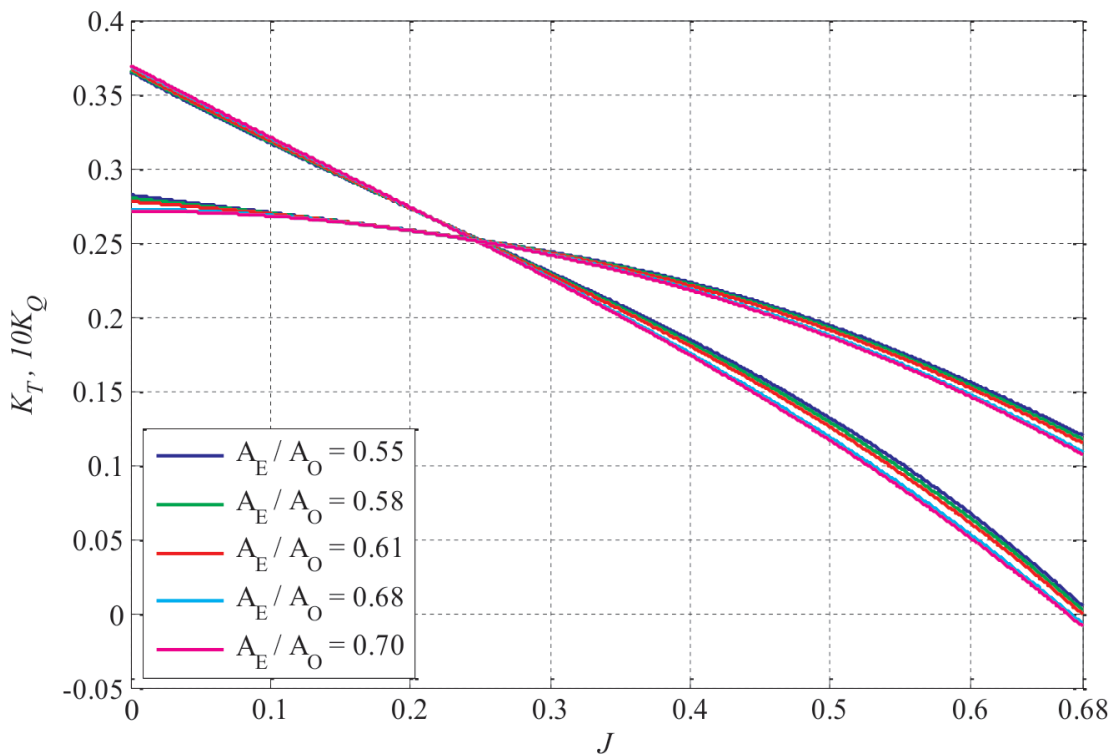

Figure 8. Neural network response for $P / D=0.8$ and $A_{E} / A_{O}=\{0.55,0.58,0.61,0.68,0.70\}$ 
The curves for which applies $A_{E} / A_{O}=\{0.55,0.70\}$ are generated on regression polynomials, and the curves for which applies $A_{E} / A_{O}=\{0.58,0.61,0.68\}$ are generated on the response of the created neural network. The remarkable approximation capabilities of the neural network in determining hydrodynamic characteristics of ducted propellers are clearly seen from Figs 7 and 8, even for the propellers which are not modelled by the regression polynomials.

\section{Conclusion}

Open water characteristics of a ducted propeller are analysed in this paper. For this purpose, its non-dimensional features are defined, and the basic properties of the used Wageningen $\mathrm{K}_{\mathrm{a}}$ screw series are listed. The regression polynomials are replaced by the matrix model which is much more convenient for further applications.

A model for determination of the thrust and torque coefficients based on the twolayered feedforward neural network which can be used for any value of the advance coefficient $J \in[0,1.34]$ and the pitch ratio $P / D \in[0.6,1.4]$ is developed. Based on the data for the propellers $K_{a} 4-55$ and $K_{a} 4-70$, both in the nozzle 19A, a model is further extended regarding the expanded area ratio from the interval $A_{\mathrm{E}} / A_{\mathrm{O}} \in[0.55,0.70]$.

Although the created model is practically usable only for the propellers $\mathrm{K}_{\mathrm{a}} 4-55$ $19 \mathrm{~A}$ and $\mathrm{K}_{\mathrm{a}}$ 4-70 19A, as well as for all other propellers of $\mathrm{K}_{\mathrm{a}}$ series with four blades which apply $A_{\mathrm{E}} / A_{\mathrm{O}} \in[0.55,0.70]$, the obtained results indicate the remarkable approximation capabilities of the neural network in determining hydrodynamic characteristics of ducted propellers. The simplified model presented in this paper is also very useful in the propulsion modelling (thrust, torque and power) of dynamically positioned vessels where these thrusters are most commonly used.

\section{Acknowledgment}

This work was supported by the University of Rijeka (Contract No. 13.09.1.1.05) and the Croatian Science Foundation (Project: Greener Approach to Ship Design and Optimal Route Planning). 


\section{References}

1. Oosterveld, M.W.C.: "Wake Adapted Ducted Propellers", Publication No. 345, Netherlands Ship Model Basin (NSMB), Wageningen, The Netherlands, 1970.

2. Matulja, D., Dejhalla, R., Bukovac, O.: "Application of an Artificial Neural Network to the Selection of a Maximum Efficiency Ship Screw Propeller", Journal of Ship Production and Design 26(2010)3, p. 199-205.

3. Roddy, R.F., Hess, D.E., Faller, W.: "Neural Network Predictions of the 4-Quadrant Wageningen Propeller Series", Hydromechanics Department Report NSWCCD-50-TR-2006/004, David Taylor Model Basin, West Bethesda, Maryland, 2006.

4. Calcagni, D., Salvatore, F., Bernardini, G., Miozzi, M.: "Automated Marine Propeller Design Combining Hydrodynamics Models and Neural Networks", Proceedings of the First International Symposium on Fishing Vessel Energy Efficiency, Vigo, Spain, 2010.

5. Kuiper, G.: "The Wageningen Propeller Series", MARIN Publication 92-001, Maritime Research Institute Netherlands (MARIN), Wageningen, The Netherlands, 1992.

6. http://www.schottel.de/marine-propulsion (December 2014)

7. Carlton, J.S.: "Marine Propellers and Propulsion", 2nd Ed., Butterworth-Heinemann, Elsevier, 2007.

8. http://www.mathworks.com (December 2014)

9. Beale, M.H., Hagan, M.T., Demuth, H.B.: "Neural Network Toolbox - User's Guide", Ver. 7.0, The MathWorks, Inc., Natick, MA, 2010.

10. Hagan, M.T., Demuth, H.B., Beale, M.H.: Neural Network Design, PWS Publishing Company, 1996. 
Marko Valčić, Roko Dejhalla

\section{Neuronska mreža za predviđanje značajki slobodne vožnje brodskog vijka u sapnici}

\section{Sažetak}

Sustav za dinamičko pozicioniranje je računalno upravljani sustav koji omogućuje održavanje pozicije i smjera napredovanja plovnog objekta pomoću brodskih vijaka i propulzora. Kako bi se poboljšala učinkovitost jako opterećenog brodskog vijka pri maloj brzini napredovanja, uglavnom se koriste azimutni propulzori s brodskim vijkom u sapnici. U radu je prikazan razvoj strukture neuronske mreže za predviđanje značajki brodskih vijaka u sapnici iz Wageningenškog niza. Cilj rada je izrada alata za predviđanje koji omogućuje procjenu značajki u slobodnoj vožnji četverokrilnih vijaka iz Ka niza u kombinaciji s ubrzavajućom sapnicom 19A. U tu svrhu, u radu se koristi dvoslojna unaprijedna neuronska mreža. Predloženi model pruža mogućnost općenitijeg modeliranja azimutnog propulzora u uobičajeno vrlo složenom hidrodinamičkom modelu propulzije dinamički pozicioniranog plovnog objekta.

Ključne riječi: dinamičko pozicioniranje, azimutni propulzor, brodski vijak u sapnici, značajke u slobodnoj vožnji, unaprijedna neuronska mreža 